\title{
Role of substrate temperature on the growth mechanism and physical properties of spray deposited lead oxide thin films
}

\author{
M. Suganya, A.R. BALU*, K. Usharani \\ PG and Research Department of Physics, AVVM Sri Pushpam College, Poondi - 613503 , \\ Thanjavur District, Tamilnadu, India
}

\begin{abstract}
Thin films of lead oxide were synthesized by cost effective spray pyrolysis technique at different substrate temperatures on glass substrates. Effect of substrate temperature on the growth mechanism and physical properties of the films was investigated. All the films were polycrystalline in nature with tetragonal structure corresponding to $\alpha$ - $\mathrm{PbO}$. The films coated at $225^{\circ} \mathrm{C}$ and $275{ }^{\circ} \mathrm{C}$ were $\left(\begin{array}{lll}1 & 0 & 1\end{array}\right)$ oriented, while the films deposited at $325^{\circ} \mathrm{C}$ and $375^{\circ} \mathrm{C}$ were $\left(\begin{array}{lll}0 & 0 & 2\end{array}\right)$ oriented. Above $375{ }^{\circ} \mathrm{C}$, the pure tetragonal nature deteriorated and the peaks corresponding to orthorhombic phase were observed. The band gap value was found to be in the range of 2.3 to $2.62 \mathrm{eV}$. All the films had a resistivity of the order of $10^{3} \mathrm{ohm}-\mathrm{cm}$. A minimum resistivity of $0.0191 \times 10^{3} \mathrm{ohm}-\mathrm{cm}$ was obtained for the film coated at $325{ }^{\circ} \mathrm{C}$. The activation energy increased with increase in substrate temperature.
\end{abstract}

Keywords: thin films; X-ray diffraction; crystal structure; energy band gap; electrical properties

(C) Wroclaw University of Technology.

\section{Introduction}

Metal oxides, such as lead oxide ( $\mathrm{PbO})$, tin oxide $\left(\mathrm{SnO}_{2}\right)$, cerium oxide $\left(\mathrm{CeO}_{2}\right)$ and titanium oxide $\left(\mathrm{TiO}_{2}\right)$, with good activity and stability at high anodic potentials are of interest because of their utilization for the electrochemical synthesis of various chemicals used in the chemical industry, and for the transformation of hazardous pollutants into less toxic compounds by electrochemical methods [13]. Lead oxide, as an important industrial material, has been widely applied in gas sensors, pigments and paints $[4,5]$. $\mathrm{PbO}$ has two polymorphic forms: the tetragonal phase $(\alpha-\mathrm{PbO})$, stable at low temperatures, and the orthorhombic phase $(\beta-\mathrm{PbO})$, stable at high temperatures [6]. The $\mathrm{PbO}$ films in both phases exhibit different levels of reflectance and they can be used as optical storage devices [7]. Lead oxide thin films have also applications as protective coatings for lead salt devices and gas sensors [8]. It is also used as an adhesion promoter for thick films [9]. Due to its low electrical conductivity and interesting semiconducting and photo conducting properties, lead oxide seems to be an

*E-mail: arbalu757@gmail.com attractive material for applications in laser technology and imaging devices [10]. Other applications are in the field of lead-containing high temperature superconducting films $[11,12]$ and high refractive index materials [13]. Lead monoxide films have also been used as an anodic material for lithium secondary batteries [14]. Being a strong oxidizing agent, lead dioxide has been used as an oxidant [15]. Preparation of lead oxide has received additional attention because lead oxide is a controlling factor in the quality of many lead based ferroelectrics [16]. The preparation of these materials is often complicated by the high volatility of lead oxide at relatively low temperatures. Furthermore, due to the existence of lead oxide in many different crystal forms [15], it is difficult to deposit as only a single oxide phase with certain crystal form. Lead oxide thin films have been laid on by both physical and chemical deposition methods. Physical methods reported in the literature include pulsed laser-assisted deposition [17], dc and rf magnetron sputtering [18], while chemical methods include spray pyrolysis $[13,14]$ and electro deposition [19]. Amongst the chemical methods used to fabricate lead oxide thin film, spray pyrolysis method is simple, inexpensive, and capable of 
producing films on large scale area for industrial applications. In spite of its simplicity, the spray technique possesses a number of advantages [20]: it offers an extremely easy way to dope films, unlike alternative techniques it requires no high quality targets and/or substrates, nor the use of vacuum at any stage; film thickness can be controlled by changing the spray parameters, it can be used over a wide temperatures range; it provides wellcompacted films. The process parameters of spray technique have a profound influence on the properties of $\mathrm{PbO}$ films. The purpose of this work is to assess the physical properties of $\mathrm{PbO}$ thin films based on the variation of substrate temperatures.

\section{Experimental details}

Thin films of $\mathrm{PbO}$ were prepared by spraying an aqueous solution $(60 \mathrm{ml})$ of lead acetate $\left[\mathrm{Pb}\left(\mathrm{CH}_{3} \mathrm{COO}\right)_{2}\right]$ onto cleaned thoroughly with organic solvent glass substrates (dimensions: $76 \mathrm{~mm}$ $\times 25 \mathrm{~mm} \times 1.4 \mathrm{~mm}$ ) using an ultrasonic agitator at different substrate temperatures by employing cost effective spray pyrolysis technique. The precursor solution was sprayed intermittently on pre-heated substrates using a spray gun. The film thickness was measured by means of weight gain method and compared with the values determined by employing a profilometer (Surftest SJ 301). The structural analysis was made using X-ray diffractometer (PANalytical-PW 340/60 X'pert PRO) with $\mathrm{CuK} \alpha$ radiation of wavelength $1.5406 \AA$ operated at $40 \mathrm{kV}$ and $30 \mathrm{~mA}$ in the $2 \theta$ range of $10^{\circ}$ to $80^{\circ}$. SEM images were obtained using a scanning electron microscope (HITACHI S-3000H). The optical transmission spectra were recorded in the 300 to $1100 \mathrm{~nm}$ wavelength region by using a Perkin Elmer UV-Vis-NIR double beam spectrophotometer (LAMDA-35). The electrical resistivity was determined using d.c. two point probe technique.

\section{Results and discussion}

\subsection{Film formation process}

When an aqueous solution of lead acetate is sprayed over hot substrates, pyrolytic decomposi- tion of the solution takes place and slightly orange colored films of $\mathrm{PbO}$ are formed. The possible chemical reaction that takes place is as follows:

$$
\mathrm{Pb}\left(\mathrm{CH}_{3} \mathrm{COO}\right)_{2}+\mathrm{H}_{2} \mathrm{O} \stackrel{\Delta}{\longrightarrow} \mathrm{PbO} \downarrow+2 \mathrm{CH}_{3} \mathrm{COOH} \uparrow
$$

Fig. 1 shows the variation of film thickness of the $\mathrm{PbO}$ films coated at different substrate temperatures.

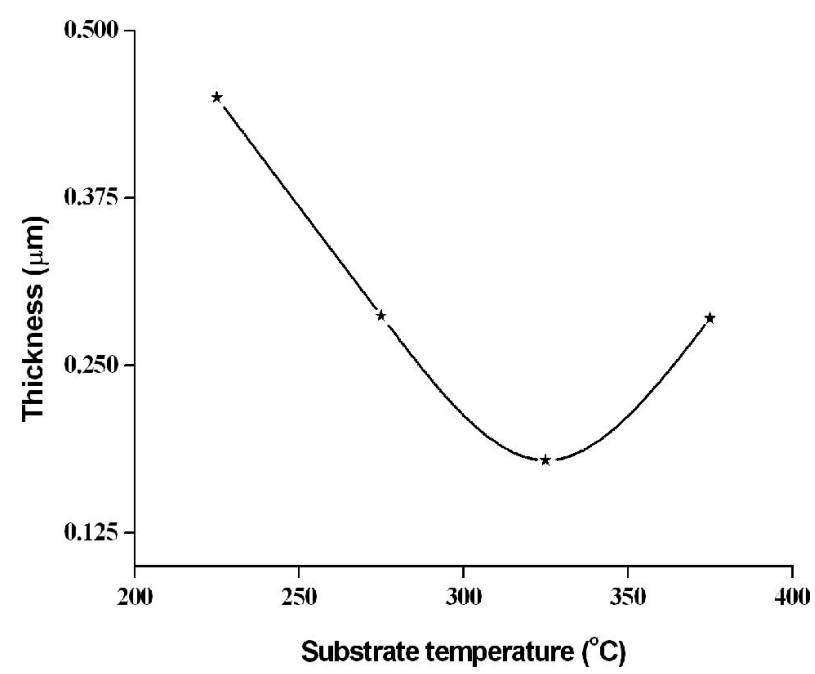

Fig. 1. Variation of $\mathrm{PbO}$ film thickness with substrate temperature.

It is observed that the film thickness decreases with an increase in substrate temperature up to $325^{\circ} \mathrm{C}$. This may be due to the reduction of precursor mass transfer to the substrate. The reduced mass transport is due to gas convection from the chamber, pushing the droplets away, which induces formation of crystallites in the vapor itself. This type of observation is reported for many oxide films prepared by the spray pyrolysis technique [21]. The low value of thickness obtained at $325{ }^{\circ} \mathrm{C}$ may be attributed to water loss [22] or removal of interlayer water with consequent formation of compact $\mathrm{PbO}$ films. Above $325^{\circ} \mathrm{C}$, the further transport of precursor droplets results in piling up of more energetic $\mathrm{PbO}$ atoms in the empty sites created due to the removal of interlayer water and hence, the thickness starts increasing. 


\subsection{Structural studies}

Fig. 2 depicts the X-ray diffraction patterns of $\mathrm{PbO}$ thin films fabricated by the spray pyrolysis technique at various substrate temperatures.
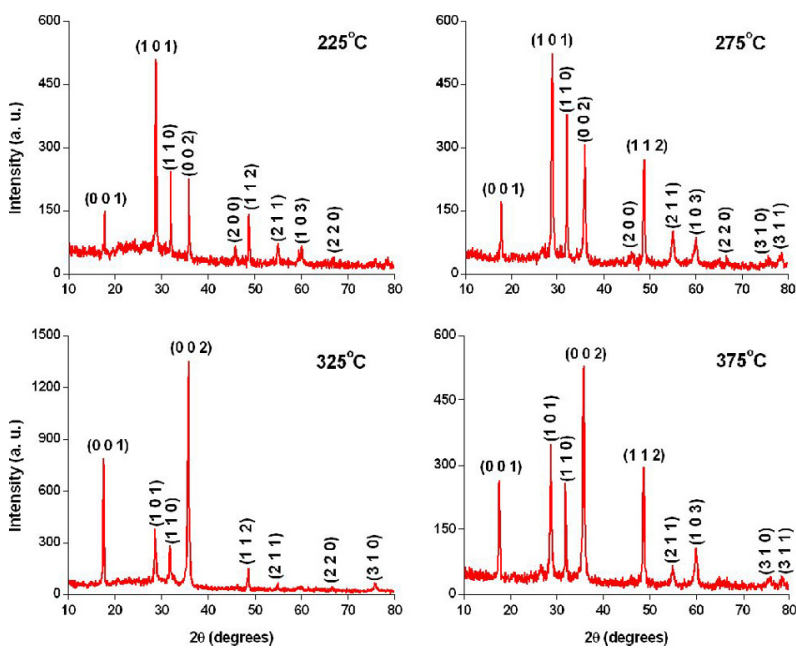

Fig. 2. XRD patterns of the PbO films coated at four different substrate temperatures.

The presence of many peaks indicates the polycrystalline structure of the films. The X-ray diffraction patterns indicated the presence of predominant peaks corresponding to $\left(\begin{array}{lll}0 & 0 & 1\end{array}\right),\left(\begin{array}{lll}1 & 0 & 1\end{array}\right),\left(\begin{array}{lll}1 & 1 & 0\end{array}\right)$, $\left(\begin{array}{lll}0 & 0 & 2\end{array}\right),\left(\begin{array}{lll}1 & 1 & 2\end{array}\right)$ and $\left(\begin{array}{lll}2 & 1 & 1\end{array}\right)$ planes for tetragonal $\mathrm{PbO}$. The comparison of observed and standard $\mathrm{d}$-spacing values of the tetragonal $(\alpha-\mathrm{PbO})$ are presented in Table 1.

The crystallites in a polycrystalline material normally have a crystallographic orientation different from that of its neighbours. This orientation of the crystallites, called the preferential orientation, may be randomly distributed with respect to some selected frame of reference. The preferential orientation factor $\mathrm{f}(\mathrm{h} \mathrm{k} \mathrm{l})$ of any plane relative to the other observed peaks is calculated by evaluating the fraction of the intensity of that particular plane over the sum of the intensities of all the peaks within the $2 \theta$ range $\left(10\right.$ to $\left.80^{\circ}\right)$. The calculated values of the preferential orientation factor $\mathrm{f}(\mathrm{h}$

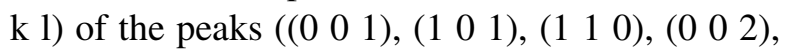
(lllll $\left.1 \begin{array}{lll}1 & 2\end{array}\right),\left(\begin{array}{lll}2 & 1 & 1\end{array}\right)$ and $\left(\begin{array}{lll}1 & 0 & 3\end{array}\right)$ ) given in Table 2 show that the value of $\mathrm{f}\left(\begin{array}{lll}1 & 0 & 1\end{array}\right)$ for the films coated at $225^{\circ} \mathrm{C}$ and $275^{\circ} \mathrm{C}$ is found to be higher compared to that of $\mathrm{f}(\mathrm{h} \mathrm{k} \mathrm{l})$ of other peaks, indicating a strong orientational growth along that plane, whereas for the films coated at 325 and $375{ }^{\circ} \mathrm{C}$ the value of $\mathrm{f}(0$ 02 ) is found to be the highest indicating a strong orientation along the $\left(\begin{array}{lll}0 & 0\end{array}\right)$ plane.

Thus, the XRD patterns reveal that the crystallographic properties of the $\mathrm{PbO}$ films fabricated at low substrate temperatures (up to $275^{\circ} \mathrm{C}$ ) are almost similar, whereas the films coated at higher substrate temperatures (greater than $300{ }^{\circ} \mathrm{C}$ ) show entirely different and interesting microstructural characteristics. The intensities of the peaks (2 00$)$ and $\left(\begin{array}{lll}2 & 2 & 0\end{array}\right)$ observed for the films coated below $300{ }^{\circ} \mathrm{C}$ are very low and their presence could not be detected for the films coated above $300{ }^{\circ} \mathrm{C}$. The predominance of $\left(\begin{array}{ll}0 & 0\end{array}\right)$ plane in the films coated at temperatures greater than $300{ }^{\circ} \mathrm{C}$ clearly shows that the growth of the crystal is such that the c-axis is perpendicular to the surface of the substrate. These observations showed that the microstructural properties of $\mathrm{PbO}$ films strictly depend on the growth mechanism, which strongly varies with respect to substrate temperature. The variation of $\mathrm{f}\left(\begin{array}{lll}1 & 0 & 1\end{array}\right)$ and $\mathrm{f}\left(\begin{array}{lll}0 & 0 & 2\end{array}\right)$ with substrate temperatures of the $\mathrm{PbO}$ films are shown in Fig. 3. The value of $f\left(\begin{array}{lll}0 & 0 & 2\end{array}\right)$ increases with substrate temperature and attains a maximum value at $325^{\circ} \mathrm{C}$, whereas the value of $\mathrm{f}(1$ 0 1) decreases and attains a minimum value confirming the influence of substrate temperature on the growth mechanism of the as-deposited samples.

In order to explain the growth mechanism, the standard deviation $(\sigma)$ is calculated by using the equation [23]:

$$
\sigma=\sqrt{\frac{I_{h k l}^{2}-\left(\sum I_{h k l}\right)^{2} / N}{N}}
$$

where I stands for the relative intensity of the (h k l) plane. Fig. 4 shows the variation of standard deviation with substrate temperature.

The high value of $\sigma$ obtained for the film coated at $325{ }^{\circ} \mathrm{C}$ suggests that the nucleation and absorption-desorption phenomenon is predominant, as a result of heterogeneous nucleation taking place at that temperature. A decrease in $\sigma$ values for the film coated at temperatures less than 
Table 1. Comparison of standard and observed d-spacing values of $\mathrm{PbO}$ thin films fabricated at different substrate temperatures.

\begin{tabular}{cccccccc}
\hline & \multicolumn{7}{c}{$\mathrm{d}(\AA)$} \\
\cline { 2 - 7 } \begin{tabular}{c} 
Substrate \\
\cline { 2 - 7 } temperature $\left({ }^{\circ} \mathrm{C}\right)$
\end{tabular} & $5.0088^{*}$ & $3.1080^{*}$ & $2.8025^{*}$ & $2.5044^{*}$ & $1.8674^{*}$ & $1.6709^{*}$ \\
\hline \hline 225 & 4.995 & 3.1056 & 2.8017 & 2.5052 & 1.8694 & 1.6713 \\
275 & 5.0195 & 3.1074 & 2.8045 & 2.5093 & 1.8709 & 1.6715 \\
325 & 5.02 & 3.1008 & 2.8 & 2.5006 & 1.8684 & 1.6706 \\
375 & 5.0246 & 3.1081 & 2.805 & 2.5101 & 1.8711 & 1.6719 \\
\hline
\end{tabular}

*Standard d-spacings (JCPDS Card No. 85-1288) for tetragonal (litharge) $\alpha$-PbO.

Table 2. Preferential orientation factor values of $\mathrm{PbO}$ films fabricated at different substrate temperatures.

\begin{tabular}{|c|c|c|c|c|c|c|c|}
\hline \multirow{2}{*}{ Substrate temperature $\left({ }^{\circ} \mathrm{C}\right)$} & \multicolumn{7}{|c|}{$\mathrm{f}(\mathrm{h} \mathrm{k} \mathrm{l)}$} \\
\hline & $f\left(\begin{array}{lll}0 & 0 & 1\end{array}\right)$ & $\mathrm{f}\left(\begin{array}{lll}1 & 0 & 1\end{array}\right)$ & $f\left(\begin{array}{lll}1 & 1 & 0\end{array}\right)$ & $f\left(\begin{array}{lll}0 & 0 & 2\end{array}\right)$ & $f\left(\begin{array}{lll}1 & 1 & 2\end{array}\right)$ & $f\left(\begin{array}{lll}2 & 1 & 1\end{array}\right)$ & $f\left(\begin{array}{lll}1 & 0 & 3\end{array}\right)$ \\
\hline 225 & 0.073 & 0.360 & 0.193 & 0.165 & 0.122 & 0.041 & 0.031 \\
\hline 275 & 0.086 & 0.303 & 0.204 & 0.168 & 0.155 & 0.043 & 0.011 \\
\hline 325 & 0.241 & 0.096 & 0.086 & 0.504 & 0.044 & 0.007 & 0.006 \\
\hline 375 & 0.139 & 0.191 & 0.123 & 0.305 & 0.161 & 0.022 & 0.048 \\
\hline
\end{tabular}

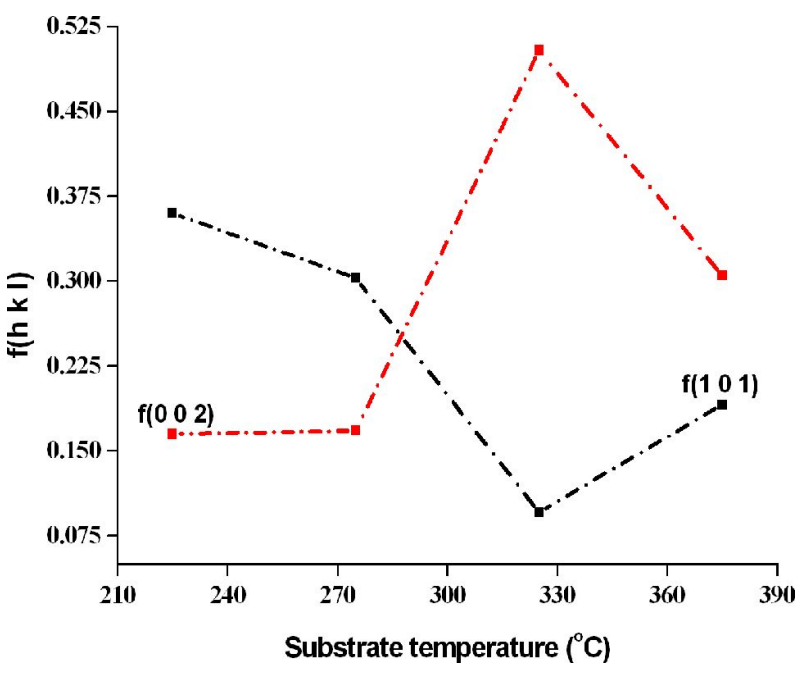

Fig. 3. Variation of preferential orientation factors $\mathrm{f}\left(\begin{array}{lll}1 & 0 & 1\end{array}\right)$ and $\mathrm{f}\left(\begin{array}{lll}0 & 0 & 2\end{array}\right)$ with substrate temperatures.

$325{ }^{\circ} \mathrm{C}$ suggests the onset of homogeneous nucleation and the low value of $\sigma$, obtained for the film coated at $375{ }^{\circ} \mathrm{C}$, might be due to the deviation from the preferred $\left(\begin{array}{lll}0 & 0 & 2\end{array}\right)$ direction. This is in accordance with Deokate et al. [24] for spray deposited fluorine doped $\mathrm{CdO}$ thin films. They obtained a high value of $\sigma$ for $\mathrm{CdO}$ films deposited at

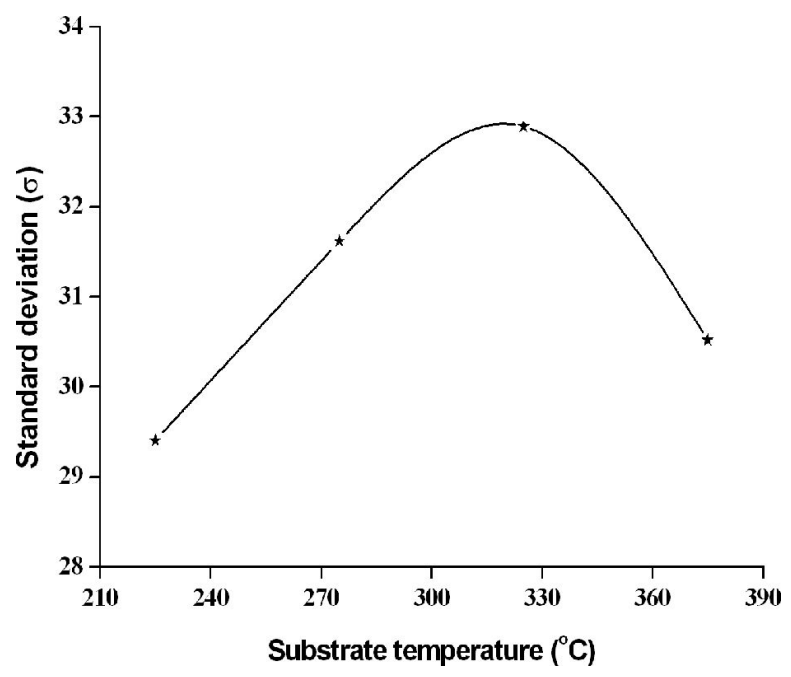

Fig. 4. Standard deviation versus growth temperature of the $\mathrm{PbO}$ films.

a high fluorine concentration, which they justified due to deviation from preferred $(200)$ direction.

No traces of lead acetate were observed in the films coated between 225 and $375{ }^{\circ} \mathrm{C}$. When the substrate temperature was below $225^{\circ} \mathrm{C}$, traces of lead acetate appeared as a minor component, which is represented by an asterisk at $2 \theta=45.88^{\circ}$ in the 
XRD pattern of the $\mathrm{PbO}$ film coated at $200{ }^{\circ} \mathrm{C}$ (Fig. 5). When the substrate temperature was increased to $225{ }^{\circ} \mathrm{C}$, the salts completely decomposed to $\alpha-\mathrm{PbO}$ (litharge) with a strong orientation along the (lll $\left.\begin{array}{lll}1 & 0 & 1\end{array}\right)$ plane. Similar results were obtained by Cruz et al. [25].

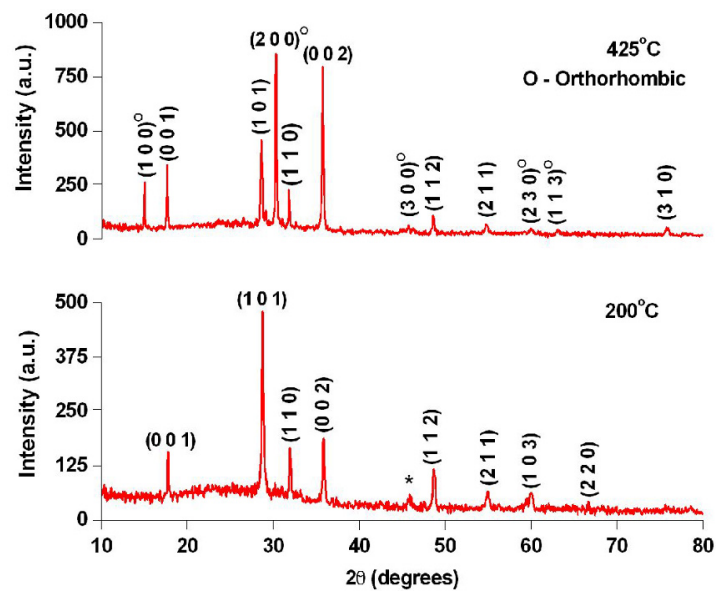

Fig. 5. XRD pattern of the $\mathrm{PbO}$ films coated at $200{ }^{\circ} \mathrm{C}$ and $425^{\circ} \mathrm{C}$.

Above $375{ }^{\circ} \mathrm{C}$, the pure tetragonal nature deteriorated and the peaks corresponding to orthorhombic phase were also observed. Thus, a mixture of both tetragonal and orthorhombic phases was observed for the $\mathrm{PbO}$ films coated above $375{ }^{\circ} \mathrm{C}$ and the orientation changed to ( $\left.\begin{array}{lll}2 & 0 & 0\end{array}\right)$ plane corresponding to orthorhombic phase as it is evident from the XRD pattern of the PbO film coated at $425^{\circ} \mathrm{C}$ (Fig. 5). This phase transition observed at $425^{\circ} \mathrm{C}$ strongly favors the fact that $\alpha$ - $\mathrm{PbO}$ (tetragonal) undergoes a transition to $\beta$-PbO (orthorhombic) at $490{ }^{\circ} \mathrm{C}$ [26]. It can be concluded therefore, that substrate temperature plays a vital role in the growth mechanism of lead oxide thin films fabricated by the spray pyrolysis technique. The crystallite size of the films for the $\left(\begin{array}{lll}0 & 0 & 2\end{array}\right)$ peak, calculated using Scherrer formula, $D=\frac{0.9 \lambda}{\beta \cos \theta}$, were found to be equal to $37.3 \mathrm{~nm}, 24.3 \mathrm{~nm}, 20.5 \mathrm{~nm}$ and $23.8 \mathrm{~nm}$ for the films coated at $225^{\circ} \mathrm{C}, 275^{\circ} \mathrm{C}, 325^{\circ} \mathrm{C}$, and $375^{\circ} \mathrm{C}$, respectively.

\subsection{Surface morphological studies}

The surface morphology of the $\mathrm{PbO}$ films was analyzed by scanning electron microscopy. The
SEM images of the films fabricated at different substrate temperatures are shown in Fig. 6.
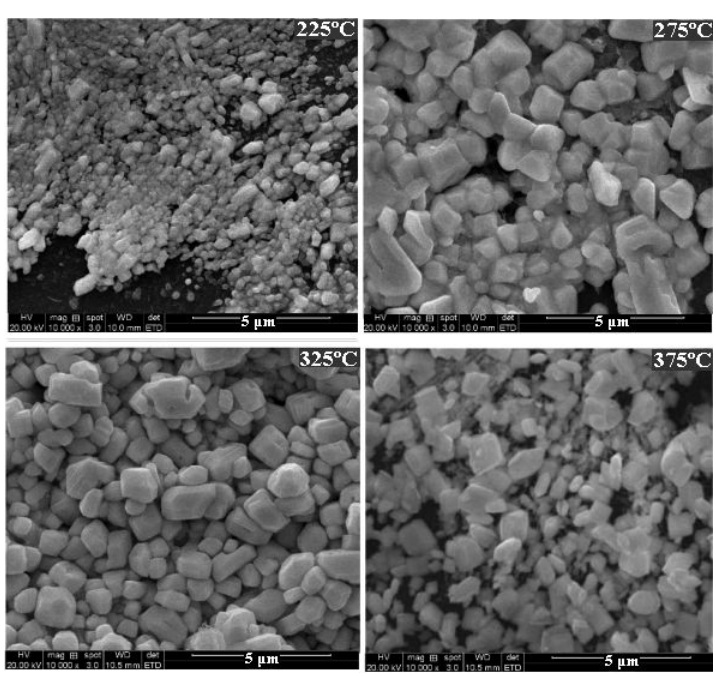

(a)

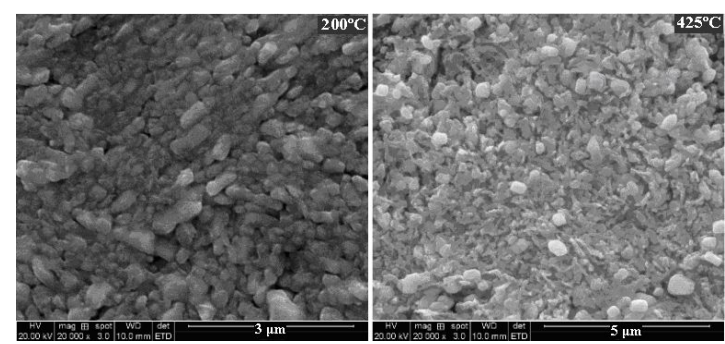

(b)

Fig. 6. SEM images of the as deposited $\mathrm{PbO}$ thin films.

Except for the film coated at $200{ }^{\circ} \mathrm{C}$ (Fig. 6b), no fused grains can be observed for all the other films and the grains appear homogeneous, suggesting that there was a uniform nucleation throughout the substrate surface. Except some small voids and pores for the film coated at $225^{\circ} \mathrm{C}$ (Fig. 6a), the SEM images of all the other films show uniform surface with well defined grain boundaries and the grains appear to be tightly packed. The films coated at $275{ }^{\circ} \mathrm{C}$ and $325{ }^{\circ} \mathrm{C}$ have predominantly cubical shaped grains, which appearing more tightly packed for the film coated at $325{ }^{\circ} \mathrm{C}$. Besides the cubical shaped grains, in the film coated at $325^{\circ} \mathrm{C}$ there are also observed spherical shaped ones. These observations about the shape of the grains are additionally confirmed by the XRD results, which reveal that the preferential 
orientation of the film coated at $275^{\circ} \mathrm{C}$ is along the (1 0 1 1) plane, whereas the film coated at $325{ }^{\circ} \mathrm{C}$ has strong preferential orientation along the $\left(\begin{array}{lll}0 & 0 & 2\end{array}\right)$ plane. In addition to cubical and spherical shaped grains, needle and hexagonal shaped ones are evident in the micrograph of the film coated at $375^{\circ} \mathrm{C}$. The decrease in the preferential orientation factor $\mathrm{f}\left(\begin{array}{lll}0 & 0 & 2\end{array}\right)$ of the film coated at $375{ }^{\circ} \mathrm{C}$ (Fig. 3) is strongly supported by the presence of hexagonal shaped grains. With further increase in substrate temperature, a mixture of tightly packed hexagonal and needle shaped grains appeared throughout the surface without any cubical or spherical shaped ones (Fig. 6b). These observations reveal that the preferential orientation of the film coated at $425^{\circ} \mathrm{C}$ has changed from (llll $\left.\begin{array}{lll}0 & 2\end{array}\right)$ plane to $\left(\begin{array}{lll}2 & 0 & 0\end{array}\right)$ plane and this fact is well supported by the XRD pattern (Fig. 5) obtained for that film. From the above mentioned discussions it can be easily understood that the shape and arrangement of the grains are highly influenced by the crystallographic orientation, which in turn depends on the growth mechanism that has been strongly dependent on the substrate temperature in this study.

\subsection{Optical properties}

Optical transmission and reflectance spectra of the $\mathrm{PbO}$ films are depicted in Fig. 7.

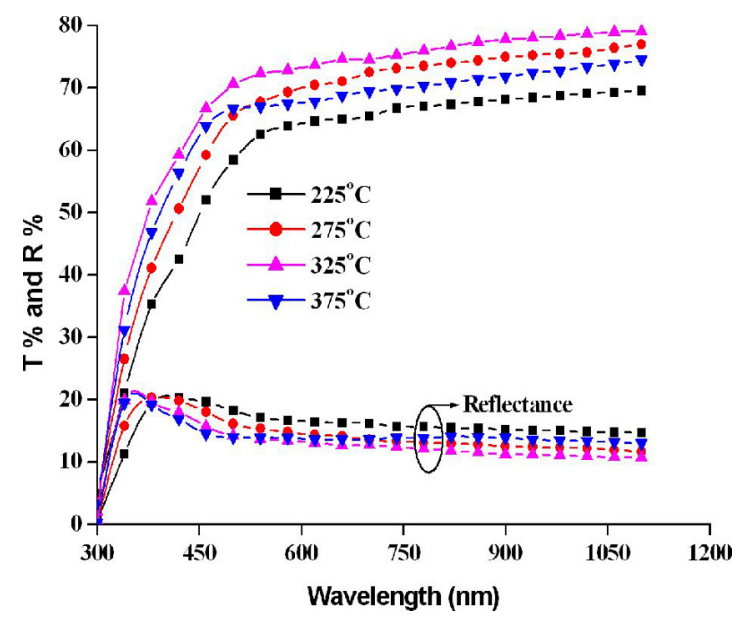

Fig. 7. Transmittance and Reflectance spectra of the $\mathrm{PbO}$ films.

Irrespective of the substrate temperature, a shoulder is noticed at $350 \mathrm{~nm}$ for all the films, which corresponds to the fundamental absorption edge due to electron excitation from the valence band to conduction band. Fig. 8 shows the effect of growth temperature on the transmittance and reflectance (at $\lambda=540 \mathrm{~nm}$ ) of the $\mathrm{PbO}$ films.

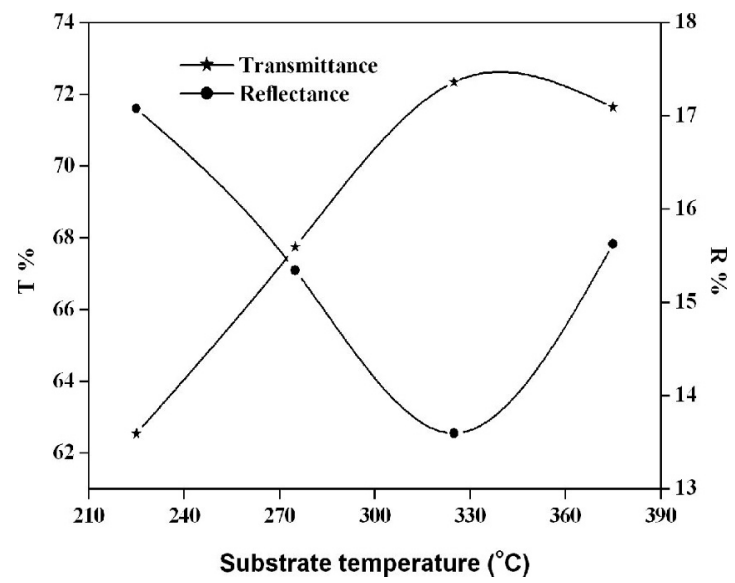

Fig. 8. Variation of $\mathrm{T} \%$ and $\mathrm{R} \%$ at wavelength $\lambda=540 \mathrm{~nm}$ with substrate temperature.

The transparency increases with an increase in substrate temperature and attains a maximum value for the film coated at $325^{\circ} \mathrm{C}$, and then it decreases. The general increase in the transmittance with decreased film thickness may be attributed to perfection and stoichiometry of the films [27]. The low transmittance at temperatures 225,275 and $375^{\circ} \mathrm{C}$ might be due to high thickness obtained for those films, which reflects in the resistivity of the films obtained at those temperatures. The reflectance decreases with an increase in substrate temperature up to $325^{\circ} \mathrm{C}$, and then it increases.

From the transmittance spectra, optical band gaps of the films were calculated using the fundamental absorption. The absorption coefficient, $\alpha$, and the incident photon energy, $\mathrm{h} \gamma$, are related by the equation [28]:

$$
(\alpha h \gamma)=A\left(h \gamma-E_{g}\right)^{n}
$$

where $\mathrm{A}$ is a constant, $\mathrm{E}_{g}$ is the band gap of the material and the exponent $\mathrm{n}$ depends on the type of transition, $\mathrm{n}=\frac{1}{2}, 2, \frac{3}{2}$ and 3 corresponding to allowed direct, allowed indirect, forbidden direct and forbidden indirect, respectively. Taking $n=\frac{1}{2}$, the 
direct optical band gap from $(\alpha \mathrm{h} \gamma)^{\frac{1}{n}}$ vs. h $\gamma$ plot (Fig. 9) has been calculated by extrapolating the linear portion of the graph to $\mathrm{h} \gamma$ axis. The intercept on the $\mathrm{h} \gamma$ axis gives the direct band gap value. The band gap values were found to be in the range of 2.3 to $2.62 \mathrm{eV}$.

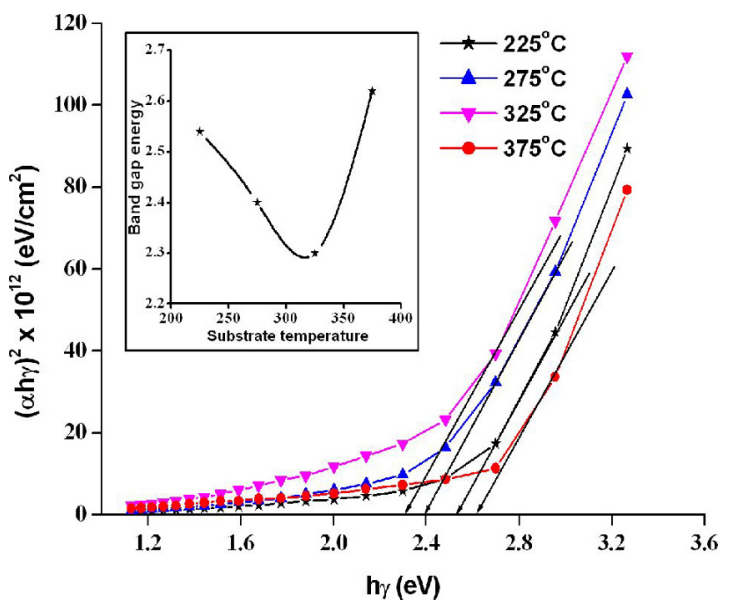

Fig. 9. $(\alpha \mathrm{h} \gamma)^{2}$ versus $\mathrm{h} \gamma$ graph of the PbO films; the inset shows the variation of band gap energy with substrate temperature.

Unfortunately, there is not much literature data available for the band gap in lead oxides. $\mathrm{E}_{g}$ values of 1.9 and $2.5 \mathrm{eV}$ were found for the tetragonal and orthorhombic structure of $\mathrm{PbO}$, respectively [28]. For $\mathrm{Pb}_{3} \mathrm{O}_{4}$ an experimental value of 2.1 to $2.2 \mathrm{eV}$ is reported, while for $\mathrm{PbO}_{2}$ a value of 4.2 has been measured for $\alpha-\mathrm{PbO}_{2}$ phase and a value of $1.5 \mathrm{eV}$ has been reported for $\beta-\mathrm{PbO}_{2}[29,30]$. The band gap values obtained in this work are consistent with the values reported in the literature [28]. The band gap value $(2.62 \mathrm{eV})$ obtained at $375{ }^{\circ} \mathrm{C}$ closely matches with the value $(2.67 \mathrm{eV})$ obtained by Hwang et al. [31] for electro-synthesized $\mathrm{PbO}$ thin films with orthorhombic crystal structure annealed at $600{ }^{\circ} \mathrm{C}$ with oxygen flow. The small deviation in the band gap value obtained might be due to the mixture of tetragonal and orthorhombic phases obtained at $375{ }^{\circ} \mathrm{C}$. The variation of $\mathrm{E}_{g}$ with substrate temperature is shown in the inset of Fig. 9. The band gap value decreases with an increase in substrate temperature up to $325{ }^{\circ} \mathrm{C}$, and after that it increases for higher substrate temperature. The decrease in band gap causes a strong red shift in the optical spectra and this is attributed to the increase of density of localized states in the energy gap. The decrease in the optical band gap of $\mathrm{PbO}$ with the increase in substrate temperature up to $325{ }^{\circ} \mathrm{C}$ could be due to the structural modification in $\mathrm{PbO}$ films as evident from the $\mathrm{XRD}$ analysis. The structural modification in the $\mathrm{PbO}$ films could be caused by the increase of either substitutional or interstitial $\mathrm{Pb}^{2+}$ ions in the $\mathrm{PbO}$ lattice. Optical constants: refractive index (n), extinction coefficient $(\mathrm{k})$ were determined using reflectance spectra and the obtained values are presented in Table 3.

The refractive index has the lowest value for the film coated at $325{ }^{\circ} \mathrm{C}$. The high value of ' $\mathrm{n}$ ' obtained for the film coated at $225{ }^{\circ} \mathrm{C}$ can be attributed to an increase of its surface roughness, which acts to decrease the effective mean free path through increased surface scattering and this fact strongly favors the reason for the reduction of its transparency. This is again supported by the high value of ' $\mathrm{k}$ ' obtained for the film coated at $225^{\circ} \mathrm{C}$, which indicates high absorption and reduced transmittance, as the variation in extinction coefficient is paralleled by the absorbance of the $\mathrm{PbO}$ films.

\subsection{Electrical properties}

The room temperature electrical resistivity $(\rho)$ was measured by two-point probe method. Fig. 10 shows the variation of electrical resistivity of $\mathrm{PbO}$ films (coated at different substrate temperatures) with various temperatures $\left(35,40,45 \ldots 75{ }^{\circ} \mathrm{C}\right)$ of the two probe set up. It is observed from the figure, that the resistivity of $\mathrm{PbO}$ films decreases with increase in temperature, indicating the semiconducting nature of the as deposited samples. All the films have a resistivity in the order of $10^{3} \mathrm{ohm}$ $\mathrm{cm}$. The variation of resistivity values obtained for $\mathrm{PbO}$ films coated at different substrate temperatures is shown in the inset of Fig. 10.

The resistivity decreases with increase in substrate temperature up to $325{ }^{\circ} \mathrm{C}$, and then it starts increasing above $325{ }^{\circ} \mathrm{C}$. A minimum resistivity value of $0.0191 \times 10^{3} \mathrm{ohm}-\mathrm{cm}$ was obtained for the film coated at $325{ }^{\circ} \mathrm{C}$, which might be caused by the following two reasons: (i) least thickness obtained as a result of the removal of $\mathrm{H}_{2} \mathrm{O}$ vapor, 
Table 3. Electrical and Optical parameters of the PbO films.

\begin{tabular}{cccc}
\hline $\begin{array}{c}\text { Substrate } \\
\text { temperature }\left({ }^{\circ} \mathrm{C}\right)\end{array}$ & $\begin{array}{c}\text { Activation energy, } \\
\mathrm{E}_{a}(\mathrm{eV})\end{array}$ & $\begin{array}{c}\text { Refractive } \\
\text { index, } \mathrm{n}\end{array}$ & $\begin{array}{c}\text { Extinction coefficient, } \\
\mathrm{k} \times 10^{-3}\end{array}$ \\
\hline \hline 225 & 0.262 & 2.24 & 77.78 \\
275 & 0.265 & 2.03 & 58.35 \\
325 & 0.278 & 1.97 & 44.852 \\
375 & 0.292 & 2.12 & 60.53 \\
\hline
\end{tabular}

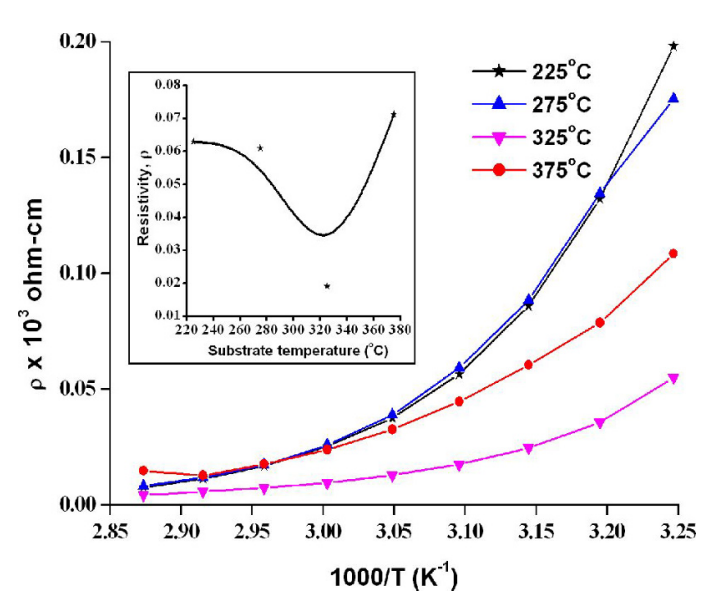

Fig. 10. Electrical resistivity versus temperature graph; the inset shows the variation of electrical resistivity with substrate temperature.

which might resist conduction between $\mathrm{PbO}$ grains. This is in accordance with Salunkhe et al. [32]. They obtained a low resistivity value for SILAR deposited $\mathrm{CdO}$ films while annealing the samples; (ii) formation of vacancies of oxygen in the structure of the material, which serve as donors and contribute to higher conductivity. Another reason for the low resistivity obtained for the film coated at $325{ }^{\circ} \mathrm{C}$ might be due to the reduced crystallite size obtained $(20.5 \mathrm{~nm})$ resulting from scattering with grain boundaries. This is in accordance with Ratheesh Kumar et al. [33].

Above $325{ }^{\circ} \mathrm{C}$, the resistivity value increases which might be due to the following reasons: (i) decrease of interstitial lead; (ii) decrease of oxygen vacancies due to the formation of compact $\mathrm{PbO}$ films at higher temperatures and (iii) defects induced at deep levels due to higher growth temperature, which trap free carriers. The trapping of free carriers by the deep level defects causes an enhancement in resistivity [34].
The activation energies of the $\mathrm{PbO}$ films were calculated using the relation:

$$
\rho=\rho_{o} \exp \left(\frac{E_{a}}{k T}\right)
$$

where $\rho$ is the resistivity at temperature $\mathrm{T}, \rho_{o}$ is a constant, $\mathrm{k}$ is the Boltzmann constant, $\mathrm{T}$ is the absolute temperature and $\mathrm{E}_{a}$ is the activation energy. The activation energy represents the location of trap levels below the conduction band. The calculated values of activation energies are presented in Table 3. It is observed that the activation energy increases with increase in substrate temperature. The values of $\mathrm{E}_{a}$ obtained in this work agree well with the values obtained by Pasha et al. [35].

\section{Conclusions}

$\mathrm{PbO}$ thin films have been deposited on glass substrates at different substrate temperatures by the spray pyrolysis technique using lead acetate as the precursor salt. The role of substrate temperature on crystallographic structure, electrical and optical properties of the deposited films has been systematically investigated. XRD studies revealed that the $\mathrm{PbO}$ films highlight a crystal transition from a preferred $\left(\begin{array}{lll}1 & 0 & 1\end{array}\right)$ orientation corresponding to tetragonal phase at temperatures $<300{ }^{\circ} \mathrm{C}$ to a $\left(\begin{array}{lll}0 & 0 & 2\end{array}\right)$ orientation at temperatures $>300$ and $<400{ }^{\circ} \mathrm{C}$. A mixture of both tetragonal and orthorhombic phases is observed for the film coated at $375{ }^{\circ} \mathrm{C}$. The preferred orientation changes to (2 00 ) plane corresponding to orthorhombic phase for the film coated at $425{ }^{\circ} \mathrm{C}$, which strongly favors the fact that $\alpha-\mathrm{PbO}$ will undergo a transition to $\beta-\mathrm{PbO}$ at higher temperatures. Film coated at $325{ }^{\circ} \mathrm{C}$ has the maximum transmittance of $79 \%$. The band gap values were found to be in the range 
of 2.3 to $2.62 \mathrm{eV}$. The electrical resistivity decreases with increase in temperature indicating the semiconducting nature of the as deposited samples. All the films have a resistivity in the order of $10^{3} \mathrm{ohm}-\mathrm{cm}$.

\section{Acknowledgements}

The authors are grateful to the Secretary and Correspondent, AVVM Sri Pushpam College (Autonomous), Poondi for his excellent encouragement and support.

\section{References}

[1] Kotz R., Stucky S., Carcer B., J. Appl. Electrochem., 21 (1991), 14.

[2] Lipp L., Pletcher D., Electrochim. Acta, 42 (1997), 1091.

[3] Comninellis C., Pulgarin C., J. Appl. Electrochem., 23 (1993), 108.

[4] Veluchamy P., Sharon M., Shimizu M., MiNOURA H., J. Electroanal. Chem., 365 (1994), 179.

[5] Ghasemi S., Mousavi M.F., Shamsipur M., KARAMI H., Ultrason. Sonochem., 15 (2008), 448.

[6] Zhang L., Guo F., LiU X., Cui J., Qian Y.T., J. Cryst. Growth., 280 (2005), 575.

[7] Chao S., Fuang Y.F., Chen Y.C., Yan L., J. Phys. D Appl. Phys., 23 (1990), 955.

[8] Madsen L.D., Weaver L., J. Am. Ceram. Soc., 81 (1998), 988

[9] Bersani M., Morten B., Prudenziati M., J. Mater. Res., 12 (1997), 501.

[10] Trinquier G., Hoffmann R., J. Phys. Chem., 88 (1984), 6696.

[11] Samoilenkov S.V., Adamov G.E., Gorbenko O.Y., Graboy I.E., Kaul A.R., Zandbergen H.W., Physica C, 338 (2000), 189.

[12] Neumayer D.A., Schulz D.L., Richeson D.S., MARKS T.J., Degrout D.C., SCHINDLER J.L., KANNEWURF C.R., Thin Solid Films, 216 (1992), 41.

[13] Thangaraju B., Kaliannan P., Semicond. Sci. Tech., 15 (2000), 542.

[14] Martos M., Morales J., Sanchez L., Ayouchi R., LEINEN D., MARTIN F., RAMOS BARRADO J.R., Electrochim. Acta, 46 (2001), 2939.

[15] Greenwood N.N., EARnshaW A., Chemistry of the Elements, $2^{\text {nd }}$ ed., Butterworth Heinemann, Oxford, 2001.
[16] Kim J.H., Kim Y., ChiEn A.T., LAnge F.F., J. Mater. Res., 16 (2001), 1739.

[17] Baleva M., Tuncheva V., J. Mater. Sci. Lett., 13 (1994), 3.

[18] Venkataraj S., Geurts J., Weis H., Jayavel R., Wuttig M., J. Vac. Sci. Technol. A, 19 (2001), 2870.

[19] Zhitomirsky I., Gal-Or L., Kohn A., Hennicke H.W., J. Mater. Sci. Lett., 14 (1995), 807.

[20] Patil P.S., Mater. Chem. Phys., 59 (1999), 185.

[21] Ayouchi A., Martin M., Leinen D., RamosBarrado J.R., J. Cryst. Growth, 247 (2003), 497.

[22] Kamal H., Elmaghraby E.K., Aly S.A., AbdelHADY K., J. Cryst. Growth, 262 (14) (2004), 424.

[23] Chitra Agashe, Takwale M.G., Marathe B.R., Bhide V.G., Sol. Energ. Mat. Sol. C., 17 (1988), 99.

[24] Deokate R.J., Pawar S.M., Moholkar A.V., Sawant V.S., Pawar C.A., Bhosale C.H., RaJPURE K.Y., Appl. Surf. Sci., 254 (2008), 2187.

[25] Cruz M., Hernan L., Morales J., Sanchez L., $J$. Power Sources, 108 (2002), 35.

[26] Ma Ying-Ren, J. Appl. Phys., 76 (1994), 2860.

[27] Mahmoud S.A., Alshomer S., Tarawnh M.A., $J$. Mod. Phys., 2 (2011), 1178.

[28] Radhakrishnan S., Kamalasanam M.N., MaHENDRU P.C., J. Mater. Sci., 18 (1983), 1912.

[29] Arai T., J. Phys. Soc. Jpn., 15 (1960), 916.

[30] Venkatara S., Geurts J., Weis H., Kappertz O., Nuoroge W.K., Jayavel R., J. Vac. Sci. Technol. A, 19 (2001), 2870.

[31] Ohhyeon Hwang, Sangsu Kim, Jong Heesuh, Shinttang Cho, Kittyun Kim, Jinki Hong, SUNUNG KIM, Nucl. Instrum. Meth. A, 633 (2011), 569.

[32] Salunkhe R.R., Dhawale D.S., Gujar T.P., LOKHANDE C.D., Mater. Res. Bull., 44 (2009), 364.

[33] Ratheesh Kumar P.M., Sudhakartha C., VIJaYAKumar K.P., Singh F., AVAsthi D.K., Abi T., Kashiwabe Y., OKRaM G.S., Kumar M., SARVEesh KuMAR., J. Appl. Phys., 97 (2005), 013509.

[34] Singh R., Arora S.K., Singh J.P., Renu Tyagi, Agarwal S.K., Kanjilal D., Mater. Sci. Eng. BAdv., 86 (2001), 228.

[35] Khadeer Pasha S.K., Chidambaram K., ViJayan N., Madhuri W., Optoelectron. Adv. Mat., $6(1-2)$ (2012), 110.

Received 2014-01-18 Accepted 2014-05-13 